\title{
The connection between microsomal epoxide hydrolase enzyme and cancer risk
}

\section{Abstract}

Microsomal epoxide hydrolase $(\mathrm{mEH})$ is a significant enzyme for biotransformation which metabolizes the conversion of different structures and varieties of xenobiotics. And also the gene of microsomal epoxide hydrolase (EPHX1) is an evolutionarily substantially protected biotransformation enzyme that functions in the transformation of enzyme epoxides to diols. In addition to this information, the enzyme can detoxify and bioaccumulate a broad variety of epoxide substrates. Polymorphic variants and mutations and in the EPHX1 gene are related with the predisposition to a diverse of diseases in humans, including cancer. This review evaluated the function of EPHX1 in human pathology, particularly in terms of cancer risk.
Volume 3 Issue 5 - 2018

\author{
Zehra Okat \\ Üsküdar Zeynep Kamil Vocational and Technical Anatolian High \\ School, Turkey

\begin{abstract}
Correspondence: Zehra Okat, Üsküdar Zeynep Kamil Vocational and Technical Anatolian High School, Istanbul. Arakiyeci Cafer Mah. Nuh Kuyusu Cad.No 4I Üsküdar/İstanbul, Tel 05066109846,Email zehraokat1980@gmail.com
\end{abstract}

Received: July 27, 2018 | Published: September 19, 2018

\section{Introduction}

Microsomal epoxide hydrolase $(\mathrm{mEH})$ has a crucial function in the metabolic biotransformation process and epoxidation catalyzes transdihydrodiols that can be conjugated to the body and excreted by the body via intermediate hydrolysis. Trans-dihydrodiols obtained from Polycyclic aromatic hydrocarbons (PAHs), one of the chemical carcinogens, in some cases have a highly toxic and mutagenic mechanism of action. For this reason, $\mathrm{mEH}$ can be said to have a two different funtion on procarcinogens for both detoxification and activation. Its role in carcinogenesis is related with exposure to distinct environmental substrates. ${ }^{1}$ Two frequent polymorphisms are involved in the coding region of the mEPHX gene. It has been noted that the $\mathrm{mEH}$ enzyme reduced enzyme activity by about $50 \%$ due to the substitution of histidine residues $(\mathrm{T} \rightarrow \mathrm{C})$ with tyrosine residues in exon 3 (Tyr113His) suggesting that these mutations may lead to cancer. ${ }^{2}$ The EPHX1 gene found in the chromosome 1q42.1 has various known variations. These polymorphisms have been shown to be connected with prostate cancer, colorectal cancer, and bladder cancer. ${ }^{3-5}$ In different studies it has been suggested that lung cancer and breast cancer are associated with risk. However, the results are uncertain. Thus, more extensive studies are needed to analyse the connection between mEPHX1 polymorphisms and the risk of cancer

\section{Breast cancer}

Some xenobiotics present in cigarette smoke may act as a carcinogenic substance in the structure of breast tissue. For example, it has been shown that PAHs can act on mammary tumors in rodents, and that human mammary cells can also create DNA attachments in the structure of proteins involved. ${ }^{6}$ As mentioned above, $\mathrm{mEH}$ enzyme is a detoxifying enzyme that functions in xenobiotic metabolism and also this enzymatic mechanisms participate in both detoxification aand activation of pro-carcinogenic molecules which is exist in tobacco smoke. Epoxides containing polycyclic aromatic derivatives are also included in the group of hydrocarbons that exist in cigarette smoke. The genetic polymorphism where takes place in the coding region of this gene also changes enzyme activity. ${ }^{2}$ A polymorphism arise from the region of the genetic exon 3; at position 113, tyrosine residues are related with decreased enzyme activity, ending up the replacement of histidine residues. On the contrary, a different polymorphism occurring in the region of the exon 4 of the genome causes arginine residues to pass instead of histidine residues at position 139, and enzyme activity to increase. It has been stated that the differences in total activity of the enzyme $\mathrm{mEH}$ activate extreme protein stability changes from catalytic changes. ${ }^{7}$ As a result, polymorphic variations in the enzyme $\mathrm{mEH}$ can change the risk degree of breast cancer. In conclusion, there is a need for current studies related to the ability of $\mathrm{mEH}$ enzyme to detoxify tobacco carcinogens in smoking women and variations in breast cancer frequency.

\section{Colon cancer}

The colon tissue throughout its life span also exposed to both free radical and oxidative damage. Major harmful stimuli functioning in this cell damage mechanism; the metabolism of endogenous products and the products of bacterial fermentation in the intestinal lumen. The biological equilibrium between damage and cell death can cause some mutations to occur, which can lead to tumor formation. Nowadays colon cancer is quite common. It has one of the highest incidences, especially in countries with a high level of development. Although the etiology of colon cancer is not fully known, it is estimated that in this pathology, a polygenic variation that determines individual sensitivity to back- ground disease in addition to those in which the diet and cigarette play a role. ${ }^{8}$ Current issues in the elucidation of this subject include; a detailed description of the roles of oncogenes, tumor suppressors, genes responsible for this mechanism, and enzymes responsible for detoxification. ${ }^{9}$ In addition, inter-individual variations of GST-M1 and GST-T1 glutathione S-transferase enzymes responsible for the catalysis and detoxification of reactive xenobiotics are also included in research topics. In addition to this information, it has been reported that a different biotransformaton enzyme which is called N-acetyltransferase 2 (NAT-2) polymorphism may have a role in progression of colon cancer. ${ }^{10,11}$ But, a series of studies have resulted in poor and inconsistent information. ${ }^{12}$ The researches about microsomal epoxidic polymorphisms in colon cancer analyzes mEPHX gene has been found to be expressed in various tissues among them colon and liver. ${ }^{2}$ The hypothesis that the polymorphisms of mEPHX may be a crucial function on sensitivity of colon cancer 
is emphasized. The variation in exon 3; by $\mathrm{C}$-substitution, the gene shifts histidine and tyrosine residues at position 113 and is connected with low enzyme activity. On the contrary, the transition from A to $\mathrm{G}$ in the region of the wild exon 4 shifts the residues of histidine and arginine at position 139 and increases enzyme activity. The mEH enzyme activity is shown to vary by more than 50 times, especially in the Caucasian population. ${ }^{13}$ Genetic polymorphism is very significant for the gene expression control after transcription.

\section{Lung cancer}

This cancer type is one of the prominent reasons of cancer death worldwide. ${ }^{14}$ Exposure to various polysaccharides is associated with aromatic hydrocarbons which is found in cigarettes, smoke or ambient air lung cancer. ${ }^{15}$ Workplace chemical agents (asbestos, arsenic, chromium, nickel and radon) and environmental agents (passive smoking and radon) can be shown to cause lung cancer. ${ }^{16}$ But in some people who are not exposed to these factors, lung cancer has also been shown to be triggered. In describing the role of differences in individual sensitivity, it is stated that nutrition, gender and general health status, including genetic background of individuals, may act a function in the cancer progression molecular process. ${ }^{17}$ Globally, lung cancer is characterized by marked regional variations, particularly in developing countries, with a more prevalent trend in North America and Europe, while developing countries are less prevalent in Africa and South America. Besides this information; lung cancer is found in males with a frequency higher than that of females. ${ }^{16}$ mEPHX1 is a long monomeric protein that encodes 455 amino acids containing nine exons. $^{2}$ Variations in the enzymatic activity of mEPHX1 resulting in such polymorphisms may give rise to interindividual variences in xenobiotics detoxification. This may lead to differences in sensitivity between individuals in chemically-carcinogenic cancers. ${ }^{18}$

\section{Bladder cancer}

In the analyzes performed about $\mathrm{mEH}$, the tissue of gonads, kidney, lung, and liver were determined that the highest concentration of microsomal epoxide hydrolase enzyme. ${ }^{19}$ Second, the enzyme also takes part in the metabolism of naturally occurring epoxides and also endogenous xenobiotics. ${ }^{19}$ The prevalent polymorphism of point mutation in exon 3 reduces enzyme activity, while the other widespread polymorphism of point mutation in exon 4 is connected with increased enzyme activity. ${ }^{2}$ The existance of homozygosity has been related with a rised risk of lung cancer and emphysema. ${ }^{20}$ Studies about hepatocellular carcinoma (HCC) have been carried out in the Caucasian population. ${ }^{21}$ Factors causing bladder cancer include cigarette smoke components and hepatocarcinogen and aflatoxin B1. In the second place, alcohol-related hepatocellular damage can be directly toxic, and the molecular mechanisms for the second factor involve: protein damage, deterioration of oxygen utilization, decreased DNA repair, the damage mediated by free radical system, the peroxidation of glutathione and lipid..$^{22}$ It is recommended that other systems involved in alcohol metabolism known to interact with this enzyme, such as cytochrome P450 and enzymes involved in detoxification, such as glutation-S-transferase. ${ }^{23}$

\section{Prostate cancer (PC)}

The etiology of PC is unknown, owing to fact that prostate carcinogenesis is a complicated process which include environmental factors and genetics. ${ }^{24}$ Carcinogenesis metabolism involves the first metabolic activation of carcinogens and the subsequent removal of activated carcinogens by mutation responsible for the replication process during the replication process, resulting in the formation of PC-inducible DNA inserts and subsequent detoxification. The previous data have shown that the enzyme $\mathrm{mEH}$ acts a bidirectional role because the ability of both tobacco and other environmental carcinogens to activate and detoxify. ${ }^{25}$ As a result, elevated activity of $\mathrm{mEH}$ may be liable for cancer protectionin order to rised detoxification of carcinogens sustained in the body, it may also increase the risk associated with its activation. Currently, many studies related to PC risk have been performed in the literature with the $\mathrm{mEH}$ gene polymorphisms, especially about exon 3/exon 4 polymorphisms. The association between $\mathrm{mEH}$ gene polymorphism, particularly exon 3 and PC, Figer et al. found a higher His113 allele frequency in the Israeli population and in Grade II tumors (5.5\%) than in Grade I tumors (5.5\%). ${ }^{26} \mathrm{~A}$ study by Mittal and Srivastava of North India showed a significant association between the allele of exon 3 gene $(\mathrm{P}<0.001)$, but not exon 4 genotypes. ${ }^{27}$ Sivonova et al. in the Slovak population, they found a moderate association between exon $4 \mathrm{Arg}$ genotypes alone or with smoking habit for PC susceptibility. However, no relation was found to be associated with the exon 3 polymorphism of the $\mathrm{mEH}$ gene. ${ }^{28}$ The connection between pesticides and $\mathrm{mEH}$ gene polymorphisms and the risk of PC was investigated by Koutros et al., this study,conducted with 2220 participants, showed an important connection with the exon 3 and exon 4 polymorphisms in the $\mathrm{mEH}$ gene. ${ }^{29}$

\section{Results}

In conclusion, human mEPHX1 gene consist of an evolutionarily high conserved metabolizing enzyme and wide variety substrate selectivity. Current analyses determined that $\mathrm{mEPHX} 1$ is an significant part of the microsomal molecular defense mechanisms according to xenobiotics toxicity. It has been announced that the mEPHX1 genetic variabilitiy is related with manifold pathological phenotypes and may promote to the improvement of cancer malignancies, particularly with environmental exposure. But, the conversion of this information into clinical practice is hampered by the lack of crystal structure of human mEPHX1 and the complexity of undiscovered connection between genotype and phenotype. ${ }^{30}$ In order to clearly assess the association of this enzyme in terms of cancer risk, a number of high-numbered analyzes involving different gene or gene-gene interactions are needed in different populations.

\section{Acknowledgments}

None.

\section{Conflict of interest}

The author declares no conflict of interest.

\section{References}

1. Zhang JH, Jin X, Li Y, Wang R, et al. Epoxide hydrolase Tyr113His polymorphism is not associated with susceptibility to esophageal squamous cell carcinoma in population of North China. World $J$ Gastroenterol. 2003;9:2654-2657.

2. Hassett C, Aicher L, Sidhu JS, et al. Human microsomal epoxide hydrolase: genetic polymorphism and functional expression in vitro of amino acid variants. Hum Mol Genet. 1994;3(3):421-428.

3. Mittal RD, Srivastava DL. Cytochrome P4501A1 and microsomal epoxide hydrolase gene polymorphisms: gene-environment interaction and risk of prostate cancer. DNA Cell Biol.2007;26(11):791-798. 
4. Liu F, Yuan D, Wei Y, et al. Systematic review and meta-analysis of the relationship between EPHX1 polymorphisms and colorectal cancer risk. PLoS One. 2012;7:e43821.

5. Zhang Z, Yu XY, Zhang GJ, et al. Low microsomal epoxide hydrolase expression is associated with bladder carcinogenesis and recurrence. Asian Pac J Cancer Prev. 2012;13(2):521-525.

6. Agarwal R, Coffing SL, Baird W. et al. Metabolic activation of benzo[g] chrysene in the human mammary carcinoma cell line MCF-7. Cancer Res. 1997;57(3):415-419.

7. Laurenzana EM, Hassett C, Omiencinsky CJ. Post-transcriptional regulation of human microsomal epoxide hydrolase. Pharmacogenetics. 1998;8(2):157-167.

8. Giovannucci E, Willett WC. Dietary factors and risk of colon cancer. Ann Med. 1994;26(6):443-452.

9. Tomlinson I, Ilyas M, Novelli M. Molecular genetics of colon cancer Cancer Metastasis Rev. 1997;16(1-2):67-79.

10. Lang NP, Chu DZJ, Hunter CF, et al. Role of aromatic amine $\mathrm{N}$-acetyltransferase in human colorectal carcinoma. Arch Surg. 1986;121(11)1259-1261.

11. Chenevix TG, Young J, Coggan M , et al. Glutathione Stransferase M1 and T1 polymorphisms: susceptibility to colon cancer and age of onset. Carcinogenesis. 1995;16(7):1655-1657.

12. Hubbard AL, Harrison DJ, Moyes C, et al. N-acetyltransferase 2 genotype in colorectal cancer and selective gene retention in cancers with chromosome 8p deletions. Gut. 1997;41(2):229-234.

13. Omiecinski CJ, Aicher L, Holubkov R, et al. Human peripheral lymphocytes as indicators of microsomal epoxide hydrolase activity in liver and lung. Pharmacogenetics. 1993;3(3):150-158.

14. Parkin DM, Bray F, Ferlay J, et al. Estimating theworld cancer burden: globocan. Int J Cancer. 2001;94(2):153-156.

15. Subramanian J, Govindan R. Lung cancer in never smokers: a review. $J$ Clin Oncol. 2007;25(5):561-570.

16. Alberg AJ, Brock MV, Samet JM. Epidemiology of lung cancer: looking to the future. J Clin Oncol. 2005;10(23):3175-3185.

17. Christiani DC. Genetic susceptibility to lung cancer. J Clin Oncol. 2006;24:1651-1652.

18. Hirvonen A. Polymorphisms of xenobiotic metabolizing enzymes and susceptibility to cancer. Environ Health Perspect. 1999;107(1):37-47.

19. Seidegard J, DePierre JW. Microsomal epoxide hydrolase properties, regulation and function. Biochim. Biophys Acta. 1983;695(3-5):251-270.

20. Benhamou S, Reinikainen M, Bouchardy C, et al. Association between lung cancer and microsomal epoxide hydrolase genotypes. Cancer Res. 1998;58(23):5291-5293.

21. McGlynn KA, Rosvold EA, Lustbader ED. et al. Susceptibility to hepatocellular carcinoma is associated with genetic variation in the enzymatic detoxification of aflatoxin B1. Proc Natl Acad Sci USA. 1995;92(6):2384-2387.

22. Lieber CS. Ethanol metabolism, cirrhosis and alcoholism. Clin Chim Acta. 1997;257(1):59-84.

23. Guengerich FP, Davidson NK. Interaction between epoxide hydrolase with itself and other microsomal proteins. Arch Biochem Biophys. $1982 ; 215(2): 462-477$

24. Arsova SZ, Eken A, Matevska N, et al. Increased oxidative/nitrosative stress and decreased antioxidant enzyme activities in prostate cancer. Clin Biochem. 2009;42(12):1228-1235.

25. Sivonova MK, Dobrota D, Matakova T, et al. Microsomal epoxide hydrolase polymorphisms, cigarette smoking and prostate cancer risk in the Slovak population. Neoplasma. 2012;59(1):79-84.

26. Figer A, Friedman T, Manguoglu AE, et al. Analysis of polymorphic patterns in candidate genes in Israeli patients with prostate cancer. Isr Med Assoc J. 2003;5(10):741-745.

27. Mittal RD, Srivastava DL. Cytochrome P4501A1 and microsomal epoxide hydrolase gene polymorphisms: Gene-environment interaction and risk of prostate cancer. DNA Cell Biol. 2007;26(11):791-798.

28. Sivonova MK, Dobrota D, Matakova T, et al. Microsomal epoxide hydrolase polymorphisms, cigarette smoking and prostate cancer risk in the Slovak population. Neoplasma. 2012;59(1):79-84.

29. Koutros S, Andreotti G, Berndt SI, et al. Xenobiotic-metabolizing gene variants, pesticide use, and the risk of prostate cancer. Pharmacogenet Genomics. 2011;21(10):615-623.

30. Radka V, David JH, Pavel S. Microsomal epoxide hydrolase 1 (EPHX1): gene, structure, function, and role in human disease. Gene.571(1):1-8. 